\title{
Here's Looking at Me: The Effect of Memory Perspective on Assessments of Personal Change
}

\author{
Lisa K. Libby \\ The Ohio State University
}

\author{
Richard P. Eibach \\ Yale University
}

\author{
Thomas Gilovich \\ Cornell University
}

\begin{abstract}
Five studies manipulated the memory perspective (1st-person vs. 3rd-person) individuals used to visually recall autobiographical events and examined its effects on assessments of personal change. Psychotherapy clients recalled their first treatment (Study 1), and undergraduates recalled past social awkwardness (Study 2). Participants who were induced to recall from the 3rd-person perspective believed, and acted as though (Study 2), they had changed more since the events occurred. Subsequent studies revealed a crucial moderator: Third-person recall produces judgments of greater self-change when people are inclined to look for evidence of change, but lesser self-change when they are inclined to look for evidence of continuity. This pattern emerged when motivation (Studies 1 and 2), goals (Study 3), instructions (Study 4), and self-esteem (Study 5) determined participants' focus on change versus continuity. Results have implications for constructivism in memory and judgment and for the ability to sustain selfimprovement efforts.
\end{abstract}

Assessments of personal change are a common part of everyday experience. "Am I getting any thinner?" "Am I still as youthful and adventuresome as I used to be?" "Are we getting over the problems in our relationship?" These assessments matter, as they guide future courses of action. "Is my new diet worth the effort?" "Will 2 weeks in the wilderness be too much for me?" "Should we continue couples therapy?" When people strive for selfimprovement, maintaining hard-won change is often difficult (Polivy \& Herman, 2002), and one factor that may promote long-term success is satisfaction with the amount of change one has achieved (Rothman, 2000). More generally, assessments of change matter because they constitute critical determinants of satisfaction and well-being (Brickman \& Campbell, 1971; Carver \& Scheier, 1990; Hsee \& Abelson, 1991).

Of course, one powerful determinant of perceived change is how much one has actually changed. People have both the motivation and capacity to monitor the tiniest variations in their habits, appearance, and performance (Gilovich, Kruger, \& Medvec, 2002), and those who have changed a great deal will typically recognize

Lisa K. Libby, Department of Psychology, The Ohio State University; Richard P. Eibach, Department of Psychology, Yale University; Thomas Gilovich, Department of Psychology, Cornell University.

We thank Dennis Regan, Erica Dawson, Joyce Ehrlinger, Nicholas Epley, and Kerri Johnson for helpful comments on this research and Kevin Van Aelst, Melissa Belkin, Elizabeth Halliburton, Matt Jarrett, Elena Kamenkovich, Eric Martz, Lottie Sweeney, and Sara Verosky for help in collecting data.

Correspondence concerning this article should be addressed to Lisa K. Libby, Department of Psychology, The Ohio State University, 1885 Neil Avenue Mall, Columbus, OH 43210. E-mail: libby.10@osu.edu, richard .eibach@yale.edu, or tdg1@ cornell.edu that they have changed more than those who have changed little. But as a rich subjectivist and constructivist tradition in social psychology suggests, perceptions of personal change are also powerfully influenced by various subjective and contextual factors. People's general theories about stability and change, for example, often distort their assessments of the way they were, as inferences about what must have been cloud or substitute for recollections of what was (Ross, 1989). For instance, the assumption that self-change programs are effective distorts people's memories of their own past selves after participating in such programs (Conway \& Ross, 1984). The desire to feel good about oneself has also been shown to influence assessments of the relationship between past and present selves, as people jump through a variety of mental hoops to maintain a close link to positive past actions and to distance themselves from previous behavior that is shameful or embarrassing (Ross \& Wilson, 2002).

In this article, we explore the impact of another subjective influence on assessments of personal change: the visual perspective from which episodes of past behavior are recalled. People often visualize autobiographical memories from either a firstperson perspective (through their own eyes) or a third-person perspective ""looking" at the self from an outside observer's perspective; Cohen \& Gunz, 2002; Frank \& Gilovich, 1989; Freud, 1907/1960; Nigro \& Neisser, 1983; Schacter, 1996). Previously, we have shown that, just as people who have changed a great deal sometimes say that their past self seems like "a different person," people are more likely to visualize an event from an outside perspective if they have changed since the event occurred than if they have not (Libby \& Eibach, 2002). Thus, self-change influences memory perspective. Here, we examine the flip side of this relation: Does memory perspective influence assessments of selfchange? Given that most people can recall a given event from 
either perspective (Frank \& Gilovich, 1989; Robinson \& Swanson, 1993), we were interested in whether adopting one perspective or the other would influence people's assessments of how much they had changed since the recalled event occurred.

Previous research has manipulated the perspective people use to visualize personal events and demonstrated pronounced effects on basic aspects of self-perception. For example, individuals are more likely to attribute their own past behavior to their dispositions when recalling from a third-person, as opposed to a first-person, perspective (Frank \& Gilovich, 1989). Imagery perspective also affects the level at which people construe their own actions. Any action (e.g., telling a joke badly) can be construed at different levels, ranging from concrete to abstract. Concrete construals (e.g., "I botched the punch line") emphasize details and define an action in isolation, whereas abstract construals of the same action (e.g., "I'm a loser") highlight its larger meaning and its broader consequences for the person committing it (Vallacher \& Wegner, 1985). Visualizing their actions from the third-person, as opposed to the first-person, perspective causes people to construe those actions at a more abstract level (Libby \& Eibach, 2004). In this way, the third-person perspective functions like other forms of psychological distancing, such as temporal distance, which accentuate the broader meaning of events by leading people to construe them on an abstract level (Trope \& Liberman, 2003). Thus, existing research shows that memory perspective influences one's basic interpretation of an event; the present studies test whether memory perspective also influences one's assessments of how much one has changed since that event occurred.

Although the present studies involve different participant populations and different types of autobiographical memories, two aspects are common to all studies. We assigned participants to picture a given autobiographical event from a particular perspective-either first-person or third-person-and subsequently asked them how much they had changed since that event had occurred. In Study 1, psychotherapy clients recalled their first day of treatment. In Study 2, undergraduates recalled a socially awkward episode from high school. We predicted that participants who were assigned to recall these events from the third-person perspective would believe, and even act (in Study 2) as if, they had changed more than those assigned to recall the events from the first-person perspective.

This prediction follows directly from the research linking the third-person perspective to abstract construal. When people recall the start of therapy or a socially awkward past self, implicit theories of change (Ross, 1989) and the motivation to maintain or create distance from a negative past self (Ross \& Wilson, 2002) should bias them to focus on the differences between their present and recalled selves. When differences are construed on an abstract level, they should have a greater impact on one's sense of selfchange: Differences construed on an abstract level (e.g., "I used to be a loser, but now I'm the life of the party") accentuate changes in the very nature of the self, whereas differences construed on a concrete level only identify changes in isolated actions (e.g., "I used to have problems delivering a punch line, but now I do not"). Given that the third-person perspective promotes abstract construal, any perceived difference should be seen as having broader implications for the nature of the self from the third-person, as opposed to the first-person, perspective. Thus, we predicted that participants' assessments of personal change would be greater when recalling autobiographical events from the third-person perspective in contexts like Studies 1 and 2.

This line of reasoning suggests that a focus on differences while comparing present and past selves is the key factor in the predicted effect of memory perspective on assessments of self-change in Studies 1 and 2. Indeed, if one looks for similarities between the present and a past self, the effect of memory perspective on self-change judgments should reverse. As is the case for differences, any perceived similarities between the present and a past self should appear to have broader implications for the nature of the self when construed on an abstract level (e.g., "I'm still a loser") than a concrete level (e.g., "I still cannot deliver a punch line"). However, whereas a more meaningful difference implies greater change in the self, a more meaningful similarity implies greater continuity in the self over time. Given that the third-person perspective accentuates the broader meaning of a recalled event, the third-person perspective should lead to perceptions of greater continuity (i.e., less change) than should the first-person perspective when people are focused on similarities between their present and past selves.

In Studies 3 through 5, we examined the influence of memory perspective on judgments of self-change in contexts in which we varied participants' theories of self-change and their motivation to distance from or embrace a past self. In so doing, we were able to test whether the effect of memory perspective on assessments of personal change is moderated by participants' focus on differences or similarities between their present and past selves. The focus on differences or similarities was determined by personal goals in Study 3, by experimental instructions in Study 4, and by individual differences in self-esteem in Study 5. Because the third-person perspective leads people to think about events in more abstract terms (Libby \& Eibach, 2004), and because abstraction accentuates the broader meaning of any given difference or similarity, we predicted that in Studies 3-5 the third-person perspective would lead to more pronounced assessments of personal change than the first-person perspective would when people were focused on differences between the present and a past self (as in Studies 1 and 2), but it would lead to diminished assessments of personal change when people were focused on similarities.

\section{Study 1}

A common goal of psychotherapy is to change the self, so individuals who have undergone psychotherapy should be particularly interested in assessing how they have changed since beginning treatment. We thus recruited participants who had been in psychotherapy and asked them to recall their first treatment session. Some participants were directed to recall this event from the first-person perspective, others from the third-person perspective. All participants were subsequently asked how much they had changed since their first treatment session. We predicted that because these participants were likely to expect change (why pay for psychotherapy otherwise?) and to be motivated to look for evidence of change, those told to recall from the third-person perspective would report that they had changed more since beginning treatment than those told to recall from the first-person perspective. 


\section{Method}

Participants. Participants were recruited from psychology and human development classes at Cornell University and received extra credit for their participation. We posted announcements in the back of lecture halls and in the social psychology laboratory seeking students who had been in psychological treatment to take part in a questionnaire study over email. Thirty-eight undergraduates responded; 26 completed the questionnaire. Twenty-one of these students were women, and the mean age of the sample was 19.6 years $(S D=0.87)$. Seventy-three percent had sought treatment for depression or anxiety; the remaining participants had sought treatment for relationship problems, sexuality confusion, eating disorders, or grief over the death of a loved one. Fifty-four percent were still in treatment at the time of the study.

Materials and procedure. The instructions that began the email questionnaire directed participants to complete the questionnaire in order, by themselves, and in one sitting. We randomly assigned participants to receive one of two versions of the questionnaire, which differed only in the visual perspective from which participants were to recall their first day of psychotherapy.

Specifically, participants were asked to "remember the first time you walked into the therapist or doctor's office for your very first psychological treatment appointment." In the first-person condition, the instructions read:

Please visualize the event FROM THE SAME VISUAL PERSPECTIVE THAT YOU ORIGINALLY HAD, in other words, LOOKING OUT AT YOUR SURROUNDINGS THROUGH YOUR OWN EYES. Please try to make your memory image as detailed as possible.

In the third-person condition the instructions read:

Please visualize the event FROM AN OBSERVER'S VISUAL PERSPECTIVE; in other words, SO THAT YOU CAN SEE YOURSELF IN THE MEMORY, AS WELL AS YOUR SURROUNDINGS. Please try to make your memory image as detailed as possible.

In both conditions, the visualization instructions were followed by a set of yes/no questions included to help participants maintain the specified visual perspective. Participants were instructed to continue picturing the memory in the specified way and to consult their image to answer the questions. In the first-person condition, the questions were

\footnotetext{
1. Can you see any furniture in the room?

2. Can you see any windows in the room?

3. Can you see anything hanging on the walls?

4. Can you see anyone else in the room?

5. If so, can you see what they are wearing?
}

In the third-person condition the questions were

1. Can you see what you were wearing?

2. Can you see what you were doing?

3. Can you see what your facial expression was?

4. Can you see how you were wearing your hair?

5. Can you see whether you were standing or sitting?

After completing the five yes/no questions, participants were instructed to hold their memory image in mind while they rated how much they had changed since their first treatment session. Participants responded by selecting a number from a scale that ranged from 0 (not at all) to 10 (completely), with a midpoint of 5 (moderately). After they had stopped picturing their memory in the prescribed fashion, participants reported the month and year of their first treatment session, the month and year they stopped treatment (if they were not still in treatment), and the reason they had sought treatment. After the study was completed, participants were fully debriefed.

\section{Results and Discussion}

The length of time since an event originally occurred is likely to influence the amount of personal change one experiences over that time. To ensure that the effects of memory perspective on assessments of change in this and all subsequent studies were independent of this potential contaminant, we used memory age as a covariate in all studies. ${ }^{1}$

Participants' change judgments in Study 1 were submitted to a one-way analysis of covariance (ANCOVA), with memory age as the sole covariate. Memory age had a significant effect: As might be expected, participants perceived more change in themselves when more time had passed since they had begun treatment; $F(1$, $23)=5.79, p<.03$. More important, participants who were instructed to visualize their first day of treatment from the thirdperson perspective perceived significantly more change in themselves since that time (adjusted $M=7.18, S D=1.83$ ) than did participants instructed to visualize their first day of treatment from the first-person perspective (adjusted $M=5.64, S D=2.24), F(1$, $23)=4.13, p=.05\left(\right.$ partial $\left.\eta^{2}=.15\right)$.

Recalling a significant autobiographical event from different visual perspectives led to different judgments about the self over time: Participants told to recall their first day of psychotherapy from the third-person perspective thought they had changed more than did those told to recall this event from the first-person perspective. This result led us to wonder whether memory perspective might also affect overt manifestations of self-changenamely, present behavior. Study 2 investigated this possibility.

\section{Study 2}

For many people, college offers the opportunity to "start over," creating a new self that overcomes the problems of an old self one wishes to leave behind (McAdams, 1993). Research by Wilson (2000) suggests that one way to move beyond an undesirable past self is to make that self feel far away in time. For example, undergraduates who were socially awkward in high school felt better about their present social skills when high school was made to feel as if it was a long time ago than when it was made to feel as if it was recent. We investigated whether instructions to adopt the third-person perspective on an undesirable high school self might have a similar effect and also addressed an additional question: Would the effect of memory perspective on assessments of self-change lead to differences in overt social behavior?

As Wilson (2000) did, we recruited undergraduate participants who said they were socially awkward in high school. We asked them to recall a particular occasion of their own social awkwardness from that period of their lives and instructed them either to use the first-person or third-person perspective to visualize it. Individuals are generally motivated to focus on differentiating their present selves from such unflattering past selves (Ross \& Wilson, 2002). We thus expected results similar to those of Study 1: Participants told to recall from the third-person perspective should see themselves as having made more progress in moving

\footnotetext{
${ }^{1}$ If we do not control for memory age, the results are still significant in all studies except Study 5, where the effects are marginally significant $(p \mathrm{~s}<.09)$.
} 
beyond their past undesirable self. We also measured participants' behavior in a social situation immediately following the memory task. We predicted that participants who had just been assigned to recall their own past socially awkward behavior from the thirdperson perspective would (as a result of seeing themselves as more different from that formerly awkward self) behave in a more socially skilled manner than those who had been assigned to recall the episode from the first-person perspective.

\section{Method}

Participants. As part of a mass pretest, Cornell undergraduates in the psychology participant pool rated what they were like in their social interactions with their peers in high school on a scale ranging from -5 (socially awkward) to +5 (socially skilled). Undergraduates who scored in the bottom third of the distribution ( 1 or below) were invited to participate. Twenty-seven individuals (16 women) from this pool $(M=-.37, S D=$ 1.71) participated in exchange for extra credit in psychology or human development classes.

Materials and procedure. Two research assistants-one male and one female-worked together to run participants in individual sessions. The behavioral measure in this study called for one of the research assistants, who was the same sex as the participant, to serve as a confederate.

When the participant arrived at the laboratory, the confederate was sitting in the waiting room, posing as another participant. The experimenter called the confederate's and participant's names and explained that they would be doing two different studies. The experimenter showed the confederate to one room and took the participant down the hall to a separate cubicle to complete a questionnaire described as a study of "experiences from late adolescence." There were two versions of this questionnaire, which differed only in the randomly assigned perspective (first-person or third-person) from which participants were to visualize the specified memory. The experimenter and confederate remained unaware of the participant's experimental condition throughout the session.

Both versions of the questionnaire had the same first page, which stated that the purpose of the study was to collect information about different kinds of experiences from late adolescence-defined as the high school years. The questionnaire explained that the participant would be asked to recall one of several types of experiences from that period of their own lives. In fact, all participants were asked to recall the same type of experience: an awkward social interaction. The cover story was meant to obscure the fact that the study was focused on social skills and that participants had been selected on that basis. The questionnaire specified that participants should recall a specific social interaction in which they were, or felt as if they were, socially awkward. Participants were asked to write down a cue word to identify that particular event to themselves.

On the next page, the directions specified that participants were to describe the memory they had recalled, but first to follow specific instructions for visualizing their memory-ostensibly to ensure that all participants went about the task in the same way. In fact, the visualization instructions differed by condition. Participants received either the firstperson or third-person instructions that were used in Study 1. However, unlike Study 1, there were no yes/no questions used as part of the manipulation. Instead, participants were asked to hold their memory image in mind using the specified perspective and to describe that image in writing. Then, still holding their memory image in mind, participants were instructed to answer the questions on the next page.

The first question was, "How socially awkward were you in high school, compared to what you are like now?" Participants answered using a scale that ranged from -5 (much LESS socially awkward in high school than now) to +5 (much MORE socially awkward in high school than now), with a midpoint of 0 (the SAME in high school as now). Then, on a scale ranging from -5 (socially awkward) to +5 (socially poised), participants rated what they were like, in general, in their social interactions with their peers at Cornell. Last, the questionnaire asked participants to "rate yourself as you CURRENTLY are (within the past 2 weeks) in relation to your same-age Cornell peers" on three dimensions-satisfied with life, selfconfident, and socially skilled. Participants made their ratings on scales ranging from 0 (much less than most of my peers) to 10 (much more than most of my peers), with a midpoint of 5 (the same as most of my peers).

When the participant had finished these ratings, the experimenter explained that since there was some time left in the session, the participant could complete another, unrelated questionnaire. The experimenter brought the participant down the hall into the room where the confederate was sitting and asked whether the confederate was finished with his or her study. The confederate replied affirmatively and the experimenter explained that the confederate could also fill out an additional questionnaire, but that first the experimenter had to go make copies of it. The experimenter left the room and then waited 5 min before returning. The participant's behavior during this time was evaluated in two ways to obtain a behavioral measure of sociability.

In anticipation of the participant's arrival in the waiting room, the confederate had turned on a concealed audio tape recorder. While the participant was in the room, the confederate did not initiate conversation with the participant, but did reply if the participant spoke. Later, a coder who was unaware of experimental condition counted the number of times the participant initiated conversation with the confederate during the waiting period. This served as one measure of sociability.

The other measure was the confederate's rating of the participant's behavior during the waiting period. After the waiting period was over, the experimenter brought the participant and confederate to individual cubicles where the participant indicated the approximate month and year of the earlier reported memory and then completed an unrelated questionnaire. Meanwhile, the confederate (who was unaware of experimental condition) rated the participant's behavior on various dimensions of sociability. The confederate indicated his or her general impression of the participant's behavior on a scale from -5 (socially awkward) to +5 (socially skilled) and indicated how much of the time the participant made eye contact using an 11-point scale ranging from none to all. Then, also by using 11-point scales, the confederate rated the participant on six bipolar dimensions: quiet-talkative, unsociable-sociable, friendly-unfriendly, extravertedintroverted, confident-unconfident, warm-cold.

The participant was then fully debriefed, probed for suspicion, and asked for consent to use the audiotape of the waiting-room interaction as part of data analysis. All participants consented.

\section{Results and Discussion}

We were interested in the effect of memory perspective on participants' beliefs about the extent to which they had overcome their social awkwardness in high school. As part of the mass pretest on which participants had rated their social skills in high school, they also rated their current social skills when interacting with their Cornell peers. These pretest ratings were used as an additional covariate in all analyses in this study to isolate, statistically, the effect of memory perspective on participants' current evaluations of themselves and on our evaluations of their behavior in this study.

Self-assessments. Participants made three ratings pertaining to the development of their social skills since high school. They rated their high school social skills relative to their present social skills, their present social skills relative to their Cornell peers, and their social interactions with their Cornell peers on an absolute scale (with higher ratings on all three measures reflecting greater current social skill). A few participants were outliers on one of these 
measures, but not on the others. To retain all participants in the analysis, we converted self-assessments on each measure to ranks and then averaged participants' ranks across the three measures to create a composite self-assessment score. The first row of Table 1 displays the mean ranks in each of the two conditions, adjusted for the covariates; higher ranks (i.e., lower numbers) denote greater self-assessed sociability in the present. Mean ranks were submitted to a one-way ANCOVA. The effect of memory age was not significant; $F(1,23)<1.00$. The effect of the other covariate, pretest self-assessments of current sociability, was significant, $F(1$, $23)=7.64, p<.05$, reflecting the fact that participants who rated themselves as more sociable on the pretest ranked higher on the dependent measures of self-assessed sociability, as well. Most intriguing, however, was the effect of memory perspective: As predicted, participants instructed to recall a past episode of socially awkward behavior from the third-person perspective ranked higher in self-assessed sociability than did participants instructed to recall the episode from the first-person perspective, $F(1,23)=4.41, p<$ .05 (partial $\left.\eta^{2}=.16\right)$.

Behavioral measures. The behavioral data from 3 participants were excluded from the analysis, 1 because of previous acquaintance with the confederate, and the other two because of suspicion that they were being watched during the waiting period. This left 24 participants-13 in the first-person condition and 11 in the third-person condition.

Because two different confederates rated participants in this study, each confederate's ratings were separately converted to $z$ scores before we analyzed them as a group. Ratings on the friendly-unfriendly, extraverted-introverted, confident-unconfident, and warm-cold dimensions were reverse-scored so that higher ratings always corresponded to greater sociability. Confederates' ratings on all six dimensions as well as their general impression of the participant's behavior and amount of eye contact were highly related (Cronbach's $\alpha=.97$ ). We therefore averaged each participant's $z$ scores on these measures to create a composite measure of sociability. The second row of Table 1 displays the mean composite score in the two conditions, adjusted for the covariates; higher scores denote greater sociability.

These composite scores were submitted to a one-way ANCOVA. Neither of the covariates had a significant effect; $F_{\mathrm{S}}<$

Table 1

Levels of Self-Assessed Sociability and Overt Behavior Adjusted for Memory Age and Pretest Self-assessments of Sociability, Study 2

\begin{tabular}{lcc}
\hline & \multicolumn{2}{c}{ Memory perspective } \\
\cline { 2 - 3 } Variable & $\begin{array}{c}\text { First person } \\
M(S D)\end{array}$ & $\begin{array}{c}\text { Third person } \\
M(S D)\end{array}$ \\
\hline $\begin{array}{l}\text { Self-assessment of sociability, } \\
\text { mean rank }\end{array}$ & $15.92(5.18)$ & $11.93(5.33)$ \\
$\begin{array}{l}\text { Confederate's rating of sociability, } \\
\text { mean } z \text { score }\end{array}$ & $-0.34(0.84)$ & $0.41(0.84)$ \\
$\begin{array}{l}\text { Number of statements made to } \\
\text { confederate }\end{array}$ & $3.36(6.49)$ & $12.25(10.88)$ \\
\hline
\end{tabular}

Note. For self-assessments, higher ranks (i.e., lower numbers) denote greater perceived sociability.
$1.05, p s>.3$. However, as predicted, participants who had been assigned to visualize their past socially awkward behavior from a third-person perspective were subsequently judged by the confederate as behaving in a more socially skilled manner than were participants assigned to use a first-person perspective, $F(1,20)=$ $4.34, p=.05$ (partial $\eta^{2}=.18$ ). Table 1 also displays the adjusted mean number of statements participants made to initiate conversation with the confederate during the waiting period. These numbers were standardized within confederate and submitted to a one-way ANCOVA. Neither of the covariates had a significant effect, memory age: $F(1,19)=2.15, p=.16$; pretest sociability: $F(1,19)=1.00, p=.33$. However, as predicted, participants in the third-person condition initiated more conversation, on average, than did those in the first-person condition, $F(1,19)=5.08, p<$ $.04\left(\right.$ partial $\left.\eta^{2}=.21\right) .^{2}$

Both behavioral measures were significantly correlated with participants' mean ranks in self-assessments of sociability, such that participants who ranked higher on self-assessments of sociability initiated more conversation with the confederate $(r=-.55$, $p<.008)$ and were also perceived by the confederate to be more sociable $(r=-.55, p<.006)$.

Mediational analysis. We conducted a mediational analysis to determine whether the effect of memory perspective on participants' self-assessments could account for the difference in the observed behavior between the two perspective conditions. First, to establish the significant relationship between the independent variable (memory perspective; first-person $=-1$, third-person $=$ +1 ) and the dependent variable (behavioral sociability), we created a single composite behavioral measure of sociability by including participants' $z$ scores for the number of statements they initiated during the waiting period in the average of the confederate's sociability ratings (already converted to $z$ scores). A regression analysis revealed that memory perspective did indeed have a significant effect on this index of behavioral sociability, $\beta=.45$, $t(19)=2.17, p<.05$, controlling for the covariates.

Next, we observed a significant relationship between the independent variable (memory perspective) and the mediator (selfassessments), $\beta=-.48, t(19)=2.44, p<.03$, controlling for the covariates. A third regression analysis revealed a significant relationship between the mediator (self-assessments) and the dependent variable (behavioral sociability), $\beta=-.53, t(18)=2.47, p<$ .03 , controlling for the effects of the independent variable (memory perspective) and the covariates. The effect of memory perspective dropped to nonsignificance in this model, $\beta=.20$, $t(18)=.93, p=.37$, thereby satisfying the fourth requirement for mediation (Baron \& Kenny, 1986). A Sobel test revealed that the change in the effect of memory perspective on behavioral sociability (from $\beta=.45$ to $\beta=.20$ ) was marginally significant $(z=$ $1.74, p=.08)$, despite the small sample size.

Thus, recalling past socially awkward behavior from a thirdperson, as opposed to a first-person, perspective caused participants in Study 2 to feel as if they had changed and were now more socially skilled than they had been before. These more positive

\footnotetext{
${ }^{2}$ Because of a technical error, the audio recording from 1 participant in the first-person condition was missing. This explains the discrepancy in degrees of freedom.
} 
self-assessments then led third-person participants to behave more sociably than did first-person participants in the subsequent interaction with the confederate. Together, the results of Studies 1 and 2 indicate that the visual perspective one uses to recall the past can affect not only subjective assessments of personal change but also relevant overt behavior.

In both of these studies, participants likely had a motivation or an implicit theory leading them to focus on differences between their present and past selves when recalling the event in question. People presumably enter psychotherapy because they hope it will help them change, and so they are likely to look for differences between their present and past selves when thinking back to the beginning of therapy (e.g., Conway \& Ross, 1984). The desire to move beyond a past socially awkward self should likewise have biased participants to focus on differences between their present and past selves in Study 2 (e.g., Ross \& Wilson, 2002). In both of these contexts, we found that the third-person perspective led to assessments of greater personal change than the first-person perspective did. These results fit with findings that the third-person perspective promotes abstract construal (Libby \& Eibach, 2004): Construing differences between the present and past selves on an abstract, as opposed to concrete, level highlights more meaningful changes in the self. This suggests that the inclination to focus on differences between the present and past selves in Studies 1 and 2 played a key role in producing the observed effect. We examined this possibility in Study 3 by recruiting participants who could be expected to vary in their tendency to look for evidence of personal change when considering a particular past action.

\section{Study 3}

Similar to our approach in Studies 1 and 2, we asked all participants to recall an instance of a certain type of past behavior-in this case, overeating - and manipulated the visual perspective from which they pictured it. However, unlike Studies 1 and 2, in which participants were likely to look for evidence of change when thinking about the past event, in this study there were two groups of participants that varied in how likely they might be to look for change in themselves when recalling the episode of overeating. One group considered it important to avoid overeating; the other group did not consider overeating to be an important concern.

We expected that whether refraining from overeating was important to participants would determine whether they were inclined to look for evidence of how they had changed or how they had remained the same when recalling the past instance of overeating. Those who consider it important to avoid overeating should be inclined to focus on differences between their present and recalled selves for any number of reasons, including a desire to distance from a negative past self, an implicit theory that one's eating habits had changed, or evidence of actual change in the self. In contrast, participants who are not concerned with avoiding overeating should be less subject to all such influences when thinking about a past instance of overeating. With no particular reason to focus on differences between the present and past self, these participants are likely to approach our tasks from an assumption of similarity. All else being equal, people tend to expect continuity in the self over time (James, 1890/1950; Ross, 1989). In addition, research on the cognitive processes underlying comparison judgments suggests that a focus on similarity is the default mindset (see Mussweiler, 2003).

If the effect of memory perspective on assessments of personal change in Studies 1 and 2 depends on an inclination to look for evidence of how the present and past selves differ, then the third-person perspective should lead to perceptions of greater self-change than the first-person perspective only among participants who consider it important to avoid overeating. Among participants not concerned with avoiding overeating, a default focus on similarities between present and past selves should produce a reversal in the effect of perspective on self-change judgments. Given that the third-person perspective accentuates the meaning of recalled actions by promoting abstract construals, focusing on similarities from the third-person, as opposed to first-person, perspective should lead to perceptions of less personal change.

\section{Method}

Participants. One hundred two Cornell undergraduates (62 women) participated in exchange for extra credit in psychology or human development classes. We recruited participants on the basis of their responses to three mass pretest questions about the importance of controlling their eating. In particular, participants rated how important it was for them to control their weight, avoid overeating, and avoid eating fatty foods. Each of these ratings was made on a scale ranging from 0 (not at all) to 6 (extremely) with a midpoint of 3 (moderately). These three ratings (Cronbach's $\alpha=.95$ ) were averaged to create an index of the importance of controlling eating. Individuals who scored in the top third of the distribution on this index ( 4 or above) were recruited to form the high-importance group $(n=51, M=4.92, S D=0.75)$ and individuals who scored in the bottom third of the distribution ( 3 or below) were recruited to form the low-importance group $(n=51, M=1.67, S D=1.11)$.

Materials and procedure. The study was described to participants as one on "eating behavior and food preferences." Participants were run in groups of 1 to 6 and were randomly assigned to one of the memory perspective conditions in a 2 (memory perspective: first-person vs. thirdperson) $\times 2$ (importance of controlling eating: high vs. low) design. The experimenter remained unaware of whether participants were high or low on importance of controlling eating and which memory perspective they were assigned to adopt.

Each participant was seated in an individual cubicle and given one of two versions of a questionnaire. The versions differed only in the visual perspective participants were directed to adopt. The first page asked participants to recall a specific occasion from the previous 6 months in which "you ate what you would define as an excessive amount of food." Participants recorded a cue word that would identify this episode to them and then turned to the next page, which contained the memory perspective manipulation.

As in Study 2, the questionnaire explained that we wanted participants to describe their memory of the episode in question, but for the purposes of standardizing responses, participants should follow specific directions for visualizing their memory while describing it. Approximately half the participants received the first-person instructions, whereas the other half received the third-person instructions. The descriptions of memory perspective were the same as those used in the previous two studies. As in Study 1, the questionnaire in Study 3 asked participants to hold their memory image in mind while answering 5 yes/no questions meant to aid participants in maintaining the specified memory perspective when forming their memory image. These were questions similar to those used in Study 1 but modified to fit an episode of overeating. After the yes/no 
questions, the questionnaire directed participants to continue to hold their memory image in mind while they described the episode.

Participants were then instructed to hold their image in mind while turning to the next page, which contained the dependent measures. The first question was, "How much has your ability to control your eating changed since the episode you are recalling?" Participants responded by circling a number on a scale that ranged from 0 (not at all) to 10 (completely). The second question asked participants to rate their past ability to control their eating relative to their current ability by choosing a number along a scale from -5 (much worse then than now) to +5 (much better then than now), with a midpoint of 0 (the same then as now). Participants were fully debriefed after completing the questionnaire.

\section{Results and Discussion}

Participants' ratings of their past ability to control their eating (i.e., the second dependent measure) were reverse-scored so that higher numbers represent assessments of greater perceived improvement. The two dependent measures were converted to $z$ scores and averaged to create a composite self-change index. Figure 1 displays the means on this index across the four conditions, adjusted for memory age; higher values represent more perceived change and lower values represent less perceived change (i.e., more perceived similarity). These self-change scores were submitted to a 2 (memory perspective: first-person vs. third-person) $\times 2$ (importance of controlling eating: high vs. low) ANCOVA, with memory age as the sole covariate. The effect of this covariate was not significant, $F(1,97)=1.62, p=.21$. However, as predicted, the interaction was significant, indicating that the effect of memory perspective on the self-change index depended on whether participants considered it important to avoid overeating, $F(1,97)=10.48, p<.003\left(\right.$ partial $\left.\eta^{2}=.10\right)$. The only other significant effect was a main effect of importance, $F(1$, $97)=20.94, p<.001$, with those for whom it was important to avoid overeating reporting more personal change since the episode in question than those for whom it was not important.

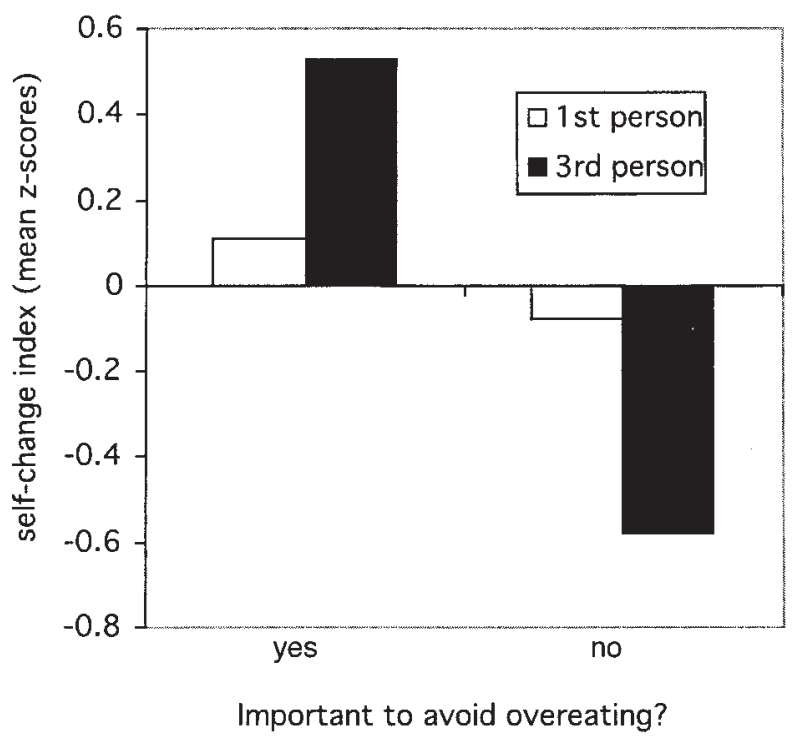

Figure 1. Adjusted mean composite self-change judgments in Study 3, by memory perspective and importance of avoiding overeating.
Further analyses verified that the shape of the interaction was consistent with our predictions. We expected that high-importance participants would tend to focus on differences between their present and past selves and thus perceive more change in their eating habits when recalling from the third-person than from the first-person perspective. A simple effects test confirmed this prediction, $F(1,97)=4.35, p<.04$. In contrast, we expected low-importance participants to adopt a default focus on similarities between their present and past selves and thus believe they had changed less when recalling from the third-person perspective than when recalling from the first-person perspective. A simple effects test confirmed this prediction as well, $F(1,97)=6.01, p<.02$.

The results of this study, then, suggest that just as the thirdperson perspective accentuates perceived change in the self when people are focused on differences between their present and past selves, the third-person perspective accentuates perceived continuity when people focus on similarities. We put this accentuation model to direct empirical test in Study 4 by explicitly manipulating participants' focus on similarities versus differences and assessing the impact of this manipulation on the relationship between memory perspective and assessments of self-change.

\section{Study 4}

Because much personal change is gradual, uneven, and uncertain, it can often seem like either continuity or change has had the upper hand. We took advantage of this fact in Study 4 to manipulate whether undergraduate participants were attending to similarities or differences when recalling a memory of their high school selves from either the first-person or third-person perspective. We predicted that participants' subsequent judgments of how much they had changed since high school would reveal an interaction between memory perspective and focus on differences or similarities between their present and past selves, analogous to the pattern observed in Study 3. Specifically, among participants led to focus on the differences between their present and high school selves, the third-person perspective should lead to judgments of greater self-change than should the first-person perspective. In contrast, among participants led to focus on the similarities between their present and high school selves, the effect of memory perspective on self-change judgments should be reversed: The third-person perspective should lead to judgments of less selfchange than should the first-person perspective.

\section{Method}

Participants. Forty-eight Cornell undergraduates (32 women) participated in exchange for extra credit in psychology or human development classes.

Materials and procedure. Participants arrived at the laboratory in groups of 1 to 5 and were escorted to individual cubicles to complete a questionnaire study on "high school memories." There were four versions of the questionnaire, created by varying memory perspective and participants' focus on continuity or change. Participants were randomly assigned to condition, and the experimenter remained unaware of each participant's condition.

The experimenter gave the questionnaire to participants in stages. The first page asked them to "recall a particular experience that you had with some close friends during your senior year of high school," to write down 
a cue word for that memory, and to estimate the month and year in which the event occurred. Next, the experimenter gave participants a sheet entitled, "Personality Information," which contained the manipulation of focus on continuity or change. Participants were given $7 \mathrm{~min}$ to describe how their personalities had stayed the same since high school or how they had changed (change instructions in brackets):

To interpret the memory data from this study more accurately it will help us to have some information on the enduring aspects of your personality [how your personality has changed over time]. Take some time to think about the ways that you have stayed pretty much the same since you were in high school [you are different now from what you were like in high school]. In the space below, describe the things about you that have been enduring from high school up through to the present [the things about you that have changed since you were in high school]. Please continue to write and think until the experimenter asks you to stop. If you need more room please use the other side of this paper

After $7 \mathrm{~min}$, the experimenter handed out the next part of the questionnaire, in which participants were asked to describe the memory they had identified on the first page of the questionnaire. As in earlier studies, the questionnaire explained that for the purposes of standardizing responses, participants were to follow specific instructions for visualizing their memory while describing it. Participants received either the first-person or third-person memory perspective instructions used in all previous studies. While holding their memory image in mind, participants answered 5 yes/no questions, similar to those used in Studies 1 and 3 but modified to be appropriate for an experience with friends in high school. Next, the questionnaire directed participants to continue to hold their memory image in mind while they described it on five lines. Participants then continued to hold their memory image in mind while they went on to the next page, which contained the dependent measures.

The first question was, "How much have you changed since this event you are recalling occurred?" Participants responded by circling a number on a scale ranging from 0 (not at all) to 10 (completely). The next question, adapted from Aron, Aron, and Smollan (1992), presented 7 Venn diagrams representing a range of no overlap to complete overlap between the self now and then. Participants were to "circle the figure which best demonstrates the relationship between you-when-the-event-occurred and younow." Participants then used a scale ranging from 0 (not at all) to 10 (completely) to indicate the extent to which the behavior they were recalling was representative of "who you are as a person right now in college." Finally, participants were asked, "How much did the transition to college affect who you are as a person today?," to which they responded on a 0 (not at all) to 10 (completely) scale. Participants were fully debriefed after completing the questionnaire.

\section{Results and Discussion}

Participants' responses to the Venn diagram were coded such that higher numbers represented less overlap between the past and present selves, and ratings of how representative the past behavior was of the present self were reverse scored so that higher ratings represented more change in the self. After making these transformations, we converted each of the four measures of self-change (Cronbach's $\alpha=.87$ ) to $z$ scores and then averaged them to provide a composite measure of perceived change in the self since the recalled event had occurred; higher values represent more perceived change and lower values represent less perceived change (i.e., more perceived similarity). Figure 2 displays the mean $z$ scores for the four conditions, adjusted for memory age. A 2 (memory perspective: first-person vs. third-person) $\times 2$ (focus:

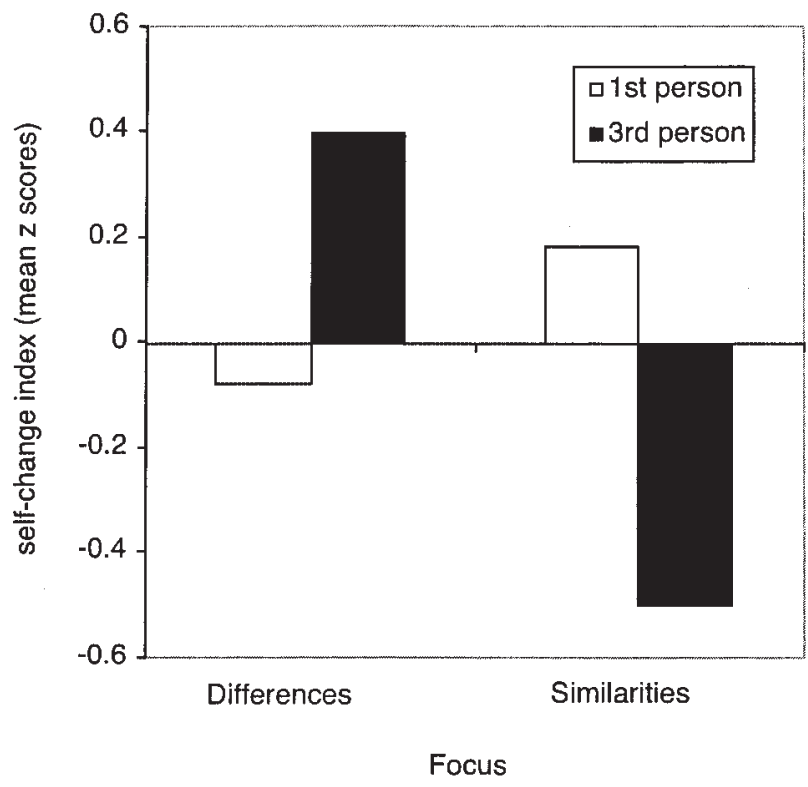

Figure 2. Adjusted mean composite self-change judgments in Study 4, by memory perspective and induced focus on difference or similarity between present and past selves.

differences vs. similarities) ANCOVA, with memory age as the sole covariate, revealed a significant interaction between memory perspective and focus, $F(1,43)=8.32, p<.007$ (partial $\eta^{2}=$ .16). The only other significant effect was that of memory age, $F(1,43)=18.63, p<.001$, reflecting the fact that participants perceived themselves to have changed more when more time had passed since the recalled event had occurred.

Simple effects tests revealed that the nature of the interaction was consistent with predictions. Among participants in the differences conditions, the third-person perspective led to judgments of greater self-change than did the first-person perspective, although the difference was only marginally significant, $F(1,43)=2.78$, $p=.10$. The effect reversed among participants in the similarities conditions: Here, the third-person perspective led to judgments of less self-change than did the first-person perspective, $F(1,43)=$ $5.85, p<.02$.

The results of Study 4 thus support our contention that whether people are biased to focus on similarities or differences between their present and recalled selves determines the effect of memory perspective on assessments of personal change. When participants were made to focus on differences, the third-person perspective led to judgments of more personal change than the first-person perspective did, but when participants were made to focus on similarities, the effect of perspective was reversed. Thus, just as the third-person perspective accentuates the broader meaning of actions (Libby \& Eibach, 2004), it also accentuates perceived similarities or differences when people are assessing self-change.

The results of Studies 1-3 highlight the importance of the third-person perspective in accentuating perceived differences between the present self and an undesirable past self. However, the results of Studies 3 and 4 suggest that the third-person perspective might also serve to minimize perceived differences between the 
present self and a positive past self, if people focus on similarities between their present selves and the positive past self. Study 5 investigated this possibility further by examining the effect of memory perspective on assessments of personal change in comparison to a past self one is motivated to embrace.

\section{Study 5}

It is not uncommon for people to be motivated to look for similarities between their present and past selves (VinitzkySeroussi, 1998), particularly when the past self is positive. Former high school athletes, for example, want to believe that they can still play as hard and well as they did in their teens despite the effects of physical aging. Baby Boomers maintain that their musical tastes are just as hip as they ever were, it is just that today's music does not measure up to the tunes they enjoyed in their youth. The most notable cinematic depiction of a person desperately trying to maintain a connection to past glory is Norma Desmond, the faded starlet in Sunset Boulevard who, when told that she "used to be big," uttered the unforgettable line, "I am big. It's the pictures that got small" (Brackett \& Wilder, 1950). Indeed, empirical research supports the notion that people are motivated to maintain psychological closeness to positive past selves, and they do so for selfenhancing reasons (Ross \& Wilson, 2002; Wilson \& Ross, 2000).

The results of Study 4 suggest that when people are focused on similarities between their present and past selves, recalling an episode from the third-person perspective tends to accentuate the similarity, leading to perceptions of less personal change than when recalling the episode from the first-person perspective. To explore this idea further, we asked participants in Study 5 to recall a positive past action-something they were proud of having done. ${ }^{3}$ We manipulated the perspective from which they visualized this event and asked them how much they had changed since that time. On the basis of the idea that people generally tend to focus on how they are similar to their positive past selves, we predicted that participants who were told to recall a proud past self from the third-person perspective would think they had changed less than those told to recall from the first-person perspective.

To provide further evidence for the idea that focusing on similarity is an essential component of the predicted main effect of memory perspective, we examined the moderating role of selfesteem. Ross and Wilson's (2002) research shows that the selfenhancing strategy of perceiving continuity when thinking about a positive past self is more prevalent among people with high self-esteem than among people with low self-esteem. We found converging evidence of this effect in a pilot study in which we asked participants to recall something they were proud of having done and to list how the person they were now was similar to and/or different from that past self. The higher the participants' self-esteem, the more biased they were toward listing similarities as opposed to differences, $t(47)=3.56, p<.001$. If the predicted main effect of perspective in the present study (Study 5) depends on similarities' being focal, then this effect should be driven primarily by participants with high self-esteem, who are more biased toward focusing on how they are similar to a proud past self.

\section{Method}

Participants. Thirty-two Cornell undergraduates (23 women), in their second or later semester at Cornell, participated in exchange for extra credit in psychology or human development classes. At the beginning of the semester, participants had completed the Rosenberg Self-Esteem Scale as part of a mass pretesting. Possible scores could range from 10 to 40 . The mean self-esteem score of participants in this study was $32.53(S D=3.48)$.

Materials and procedure. Participants arrived at the laboratory in groups of 1 to 5 and were seated in individual cubicles to complete a questionnaire study on "Cornell memories." Participants were randomly assigned to perspective condition, and the experimenter remained unaware of participants' self-esteem levels and experimental condition.

The experimenter gave the questionnaire to participants in stages. The first page contained the memory prompt, adapted from Ross and Wilson (2002, Study 3). Specifically, the instructions stated:

Please think of something you did during your first semester at Cornell that you are quite proud of. This might be a special achievement or something kind or intelligent you said or did or anything else you did that you are quite proud of.

After thinking of an event that fit the description, participants estimated the month and year in which it occurred.

The next page contained the memory perspective manipulation, which followed the same format as in Studies 1, 3, and 4. After participants had described their memory, while visualizing it from the specified perspective, they completed the dependent measure, which was, "How much have you changed since the event you are recalling occurred?" Participants responded by circling a number on a scale ranging from 0 (not at all) to 10 (completely). Participants were fully debriefed after completing the questionnaire.

\section{Results and Discussion}

To take advantage of the continuous measure of self-esteem in this study, we used regression analyses instead of analyses of covariance to analyze the data. The continuous variables, selfesteem and memory age, were centered by subtracting the sample mean. Then, participants' self-change judgments were regressed onto self-esteem, memory perspective (first-person $=-1$, thirdperson $=+1$ ), their interaction, and memory age (the covariate). Table 2 displays the results.

There was a marginally significant effect of the covariate, indicating that participants-not surprisingly-thought they had changed more the further in the past the recalled event had occurred. More interesting are the effects involving memory perspective. As predicted, the main effect of memory perspective was significant-the third-person perspective led participants to see less change in themselves since the time of the recalled event than did the first-person perspective. Finally, the analysis also revealed the predicted significant interaction between memory perspective and self-esteem. To investigate this interaction more closely, we followed a procedure outlined by Aiken and West (1991): We

\footnotetext{
${ }^{3}$ We hoped to manipulate whether participants recalled a proud or embarrassing past action. However, the manipulation failed (and the data from those asked to recall an embarrassing event are not reported) because half the participants told to recall an embarrassing past action they had engaged in reported something someone else had done that was embarrassing to them.
} 
defined high and low self-esteem as one standard deviation above and below the sample mean, respectively; plotted the analysis's predicted self-change values at those levels of self-esteem (see Figure 3); and conducted further regression analyses to test the effects of memory perspective at those levels of self-esteem.

We have argued that a focus on similarities is essential in causing people who recall an episode from the third-person perspective to believe they have changed less than those told to recall it from the first-person perspective. In this study, in which participants recalled a proud event, we expected high-self-esteem participants to be more biased toward focusing on how they were similar to their positive past self than low-self-esteem participants would be. Thus, we expected that the effect of memory perspective would be most pronounced among high-self-esteem participants. As Figure 3 indicates, this is precisely what happened. Among high-self-esteem participants, there was a significant effect of memory perspective such that recalling a proud moment from the third-person perspective led to significantly less perceived selfchange than did recalling the event from the first-person perspective, $\beta=-.70, t(27)=3.01, p<.007$. Among low-self-esteem participants, in contrast, there was no significant effect of memory perspective, $\beta=.04, t(27)=.18, p=.86$.

Together with the results from the earlier studies, the results of Study 5 point to the impact of memory perspective on present well-being. Achieving a sense of distance from one's negative past actions and a sense of connection to one's positive past actions promotes a favorable view of the present self (Ross \& Wilson, 2002). Studies 1-3 suggest that the third-person perspective enhances perceptions of change when people are focused on how they are different from their negative past selves. Study 5 indicates that the third-person perspective can also serve to promote perceptions of continuity between the present self and a positive past self when people are inclined to look for similarities.

\section{General Discussion}

Autobiographical memory is an important aspect of selfknowledge, and imagery is a significant component of autobiographical memory (Pillemer, 1998). Our research shows that a qualitative difference in autobiographical memories can influence quantitative assessments of personal change. In Studies 1 and 2, participants who were instructed to recall events from the thirdperson perspective perceived more personal change than those who were instructed to recall events from the first-person perspective. These studies involved contexts in which expectations of personal change and motivation for improvement were salient,

Table 2

Regressing Self-Change Judgments Onto Self-Esteem and Memory Perspective, Study 5

\begin{tabular}{lcl}
\hline \multicolumn{1}{c}{ Predictor } & $\beta$ & $t(27)$ \\
\hline Memory age & .34 & $1.97 \dagger \dagger$ \\
Self-esteem & .01 & 0.08 \\
Memory perspective & -.33 & $2.04 \dagger$ \\
Self-Esteem $\times$ Memory Perspective & -.36 & $2.23^{*}$ \\
\hline
\end{tabular}

$\dagger \dagger p<.10 . \quad \dagger p=.05 . * p<.05$.

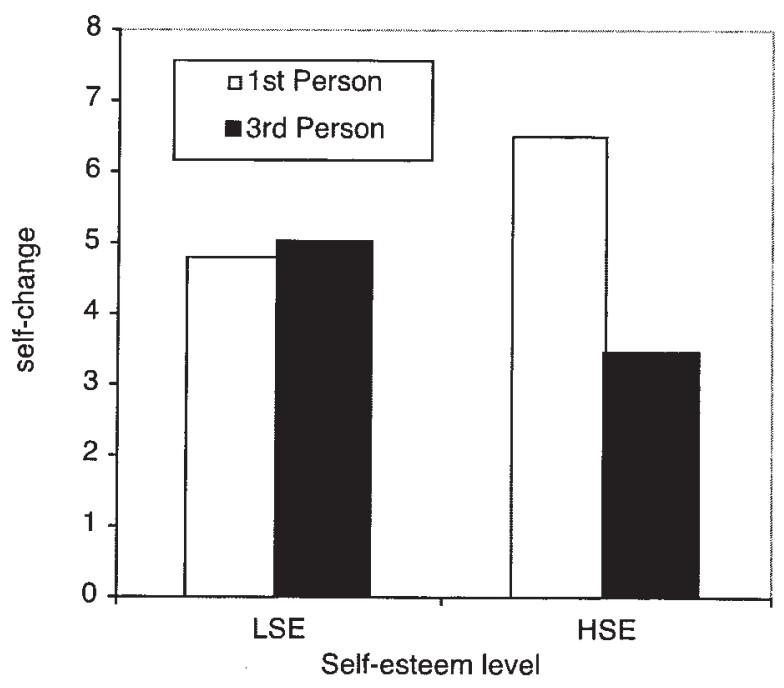

Figure 3. Regression-derived self-change judgments, based on memory perspective and self-esteem, controlling for memory age (Study 5). Low self-esteem (LSE) and high self-esteem (HSE) are defined as one standard deviation below and above the sample mean, respectively.

thus biasing participants to focus on the differences between their present and past selves as they recalled the events in question.

Subsequent studies revealed that whether a person focuses on differences or similarities between the present and past selves is crucial in determining the effect of memory perspective on assessments of self-change: When people are inclined to focus on differences, the third-person perspective leads to perceptions of greater self-change than the first-person perspective does, but when people are inclined to focus on similarities, the effect of memory perspective on assessments of self-change reverses. This pattern emerged in Study 3 when personal goals affected participants' focus on similarities or differences between the present and past selves. The pattern also emerged in Study 4 when participants were explicitly directed to focus on similarities or differences between the present and past. Finally, in Study 5, an individual difference variable - self-esteem-determined the extent to which participants focused on similarities and thus moderated the effect of perspective on assessments of self-change. We discuss the implications of these results for understanding constructive processes in memory and judgment, maintenance of self-improvement and well-being, and the nature of the self-concept.

\section{Constructive Processes in Comparison Judgments}

Assessments of personal change involve judgments of the degree of similarity (or difference) between one's present and past selves. But doing so on "objective" grounds presents something of a challenge, because there is an infinite number of potential dimensions on which any two items might be similar or different (Murphy \& Medin, 1985). Constructive processes therefore play a crucial role in comparison judgments, and Tversky's (1977) constructivist account offers a useful framework for understanding such assessments. This framework has provided insight into the determinants of social comparison judgments (Mussweiler, 2001, 
2003), for example, and we think it also provides an illuminating perspective for understanding our results regarding selfcomparisons across time.

According to Tversky's model, similarity judgments can be understood by considering constructive influences on two factors: the type of evidence a person looks for in the process of making the judgment and the amount of evidence a person finds. In his studies, participants were asked to compare pairs of stimuli, such as China and Japan. Because of confirmation bias, the framing of the task influenced the type of evidence participants looked for: shared features when the task was to assess similarity, but distinctive features when the task was to assess difference. Participants' familiarity with the stimuli influenced the amount of the evidence they found. When the stimuli were familiar (e.g., China and Japan) participants looking for shared features found many more of them than when stimuli were unfamiliar (e.g., Paraguay and Ecuador). But participants looking for differences likewise found more distinctive features between the familiar pairs than the unfamiliar pairs. These influences on the type of evidence participants looked for and the amount of evidence they found produced the counterintuitive finding that two familiar stimuli were perceived as both more similar to and more different from one another than two unfamiliar stimuli.

Our finding that recalling events from the third-person perspective led to both larger and smaller judgments of personal change is reminiscent of Tversky's counterintuitive finding. As did Tversky, we found that the type of evidence participants were looking for-in our case, similarities or differences between their present and past selves-was a crucial determinant of their judgments. This was true regardless of whether it was a prior expectation, personal goals, direct instructions, or self-esteem that led participants to focus on similarities or differences.

The other crucial determinant of participants' assessments of personal change was the perspective from which they visualized the past event. In light of other research showing that the thirdperson perspective promotes abstract construal, the effect of memory perspective in the present studies can be understood as impacting the magnitude and import of the evidence people found when looking for differences or similarities between their present and past selves. We contend that when people identify a difference (or similarity) between a present and past self, and then picture that past self from the first-person or third-person perspective, they perceive that difference (or similarity) to be more consequential from the third-person perspective. Thus, participants perceived more change from the third-person than from the first-person perspective if they were looking for differences, but more continuity from the third-person than from the first-person perspective if they were looking for similarities. Consistent with this account, we have shown elsewhere that directly manipulating the level at which people construe a given past behavior affects judgments of similarity and change in ways that closely parallel our manipulations of memory perspective (Libby \& Eibach, 2004).

The present studies demonstrate that visual perspective in memory can influence the construction of self-knowledge. There are, of course, many other ways that the recall of autobiographical events can be channeled and such manipulations may also have significant effects on self-knowledge and understanding. For example, people can be instructed to "relive" a previous experience, perhaps with a focus on their earlier emotions or internal states, or be instructed to focus on their overt behavior. People can also be instructed to recall how an episode occurred or why it occurred (Strack, Schwarz, \& Gschneidinger, 1985). In light of the present findings, it may be profitable to explore in future research whether these dimensions likewise influence the construction of self-knowledge.

\section{Perspective, Self-Improvement, and Well-Being}

People often aspire to change in any number of ways, from reforming their eating habits to improving their social abilities to overcoming negative personality traits. The process of behavioral change involves two stages: initiating change and maintaining it. As yo-yo dieters know too well, the maintenance phase can often be more difficult (Polivy \& Herman, 2002; Rothman, 2000). One reason for this difficulty may be that the psychological factors that motivate initiation are not necessarily the same as those that support maintenance. So, succeeding at long-term maintenance requires a shift in strategies. For example, the decision to initiate change is based in part on favorable expectations, but the effort to "stay the course" depends on perceived satisfaction with the amount of change that has occurred (Rothman, 2000). Thus, Rothman (2000) has proposed that comparisons with the desired ideal self should be more prominent (and motivating) at initiation but that during maintenance people would be well served to switch to comparisons with their past, prechange selves. Although one may not have reached the ideal, some progress may have been made, and a focus on how the current state differs from the starting point can thus induce satisfaction with one's efforts - and increase the motivation to continue trying. Rothman argued that the failure to make this shift in focus when transitioning from initiation to maintenance contributes to widespread failure during the maintenance phase.

The present research suggests that recalling an old, prechange self from the third-person perspective might help individuals deal with the challenge of maintaining personal change. Having already initiated some change in behavior, people in the maintenance phase are especially likely to focus on differences between their present and past selves. Recalling the prechange self from the third-person perspective should therefore accentuate perceptions of change. Greater perceived change is likely to lead to greater satisfaction with one's efforts thus far and, therefore, to make it easier to summon the resources necessary to maintain one's efforts.

Eliminating bad habits is one way to enhance present wellbeing; connecting to positive elements of one's past is another. The results of Study 5 suggest that the third-person perspective can facilitate the latter as well. Among participants who were inclined to look for a connection to a positive past self, those told to recall a pertinent past event from a third-person perspective perceived less change in themselves than did those told to recall the event from a first-person perspective. Ross and Wilson's (2002) research indicates that psychologically distancing oneself from negative past selves and remaining close to positive past selves promotes well-being. Our research indicates that recalling events from the third-person perspective can facilitate both effects. 


\section{Content and Experience of Self-Knowledge}

Traditionally, social psychological research on the self-concept has focused on the content and cognitive organization of selfrelated knowledge (e.g., Markus, 1977; Markus \& Nurius, 1986; Ross, 1989; Sanitioso, Kunda, \& Fong, 1990). More recent research suggests, however, that a complete understanding of the self-concept requires attention to the experience of accessing selfknowledge. Schwarz et al. (1991) have found that the ease with which participants recall a specified number of assertive or unassertive behaviors can have more of an impact on their sense of their own assertiveness than the content of the evidence they recall. Ross and Wilson's work (Ross \& Wilson, 2000, 2002; Wilson, 2000; Wilson \& Ross, 2001) has focused on another experiential aspect of memory: subjective temporal distance. Their research indicates that the effect of one's own past behavior on one's current self-appraisal depends on how long ago that past behavior feels in time.

The present studies contribute to an understanding of how experiential aspects of self-knowledge impact self-evaluations. We have shown previously that the self-concept compatibility of a past behavior influences the perspective from which that behavior is spontaneously recalled (Libby \& Eibach, 2002). The present studies advance our understanding of the flip side of this relationshipthat the perspective people use to visualize autobiographical events influences their assessments of how much they have changed since those events occurred. In all five studies reported here, the memories were cued before participants knew the perspective from which they would be asked to visualize. The effects we observed were therefore not the result of any objective differences in the types of actions participants recalled.

Previous work in this domain has focused on general theories of stability and change as determinants of perceived changes in the self. The present studies show that it is not only general theories that matter, but also the way one visualizes the past self. When describing issues for which subjective factors strongly influence one's stance, people sometimes say, "it depends on how you look at it." Our research suggests that there is literal truth in this statement when it comes to assessments of personal change.

\section{References}

Aiken, L., \& West, S. (1991). Multiple regression: Testing and interpreting interactions. Newbury Park, CA: Sage.

Aron, A., Aron, E. N., \& Smollan, D. (1992). Inclusion of other in Self Scale and the structure of interpersonal closeness. Journal of Personality and Social Psychology, 63, 596-612.

Baron, R. M., \& Kenny, D. A. (1986). The moderator-mediator variable distinction in social psychological research: Conceptual, strategic, and statistical considerations. Journal of Personality and Social Psychology, 51, 1173-1182.

Brackett, C. (Producer), \& Wilder, B. (Director). (1950). Sunset Boulevard [Motion picture]. Hollywood, CA: Paramount Pictures.

Brickman, P., \& Campbell, D. T. (1971). Hedonic relativism and planning the good society. In M. H. Appley (Ed.), Adaptation level theory: A symposium (pp. 287-304). San Diego, CA: Academic Press.

Carver, C. S., \& Scheier, M. F. (1990). Origins and functions of positive and negative affect: A control-process view. Psychological Review, 97, $19-35$.

Cohen, D., \& Gunz, A. (2002). As seen by the other ...: Perspectives on the self in the memories and emotional perceptions of Easterners and Westerners. Psychological Science, 13, 55-59.

Conway, M. A., \& Ross, M. (1984). Getting what you want by revising what you had. Journal of Personality and Social Psychology, 47, 738748.

Frank, M., \& Gilovich, T. (1989). Effect of memory perspective on retrospective causal attributions. Journal of Personality and Social Psychology, 57, 399-403.

Freud, S. (1960). Childhood memories and screen memories. In J. Strachey (Ed.), The standard edition of the complete psychological works of Sigmund Freud (Vol. 6, pp. 43-52). London: Hogarth Press. (Original work published 1907)

Gilovich, T., Kruger, J., \& Medvec, V. H. (2002). The spotlight effect revisited: Overestimating the manifest variability of our actions and appearance. Journal of Experimental Social Psychology, 38, 93-99.

Hsee, C. K., \& Abelson, R. P. (1991). Velocity relation: Satisfaction as a function of the first derivative of outcome over time. Journal of Personality and Social Psychology, 60, 341-347.

James, W. (1950). The principles of psychology (Vol. 1). New York: Dover Publications. (Original work published 1890)

Libby, L. K., \& Eibach, R. P. (2002). Looking back in time: Self-concept change affects visual perspective in autobiographical memory. Journal of Personality and Social Psychology, 82, 167-179.

Libby, L. K., \& Eibach, R. P. (2004). Seeing meaning in action: Imagery perspective and action identification. Manuscript in preparation.

Markus, H. (1977). Self-schemata and processing information about the self. Journal of Personality and Social Psychology, 35, 63-78.

Markus, H., \& Nurius, P. (1986). Possible selves. American Psychologist, 41, 954-969.

McAdams, D. P. (1993). The stories we live by: Personal myths and the making of the self. New York: William Morrow.

Murphy, G. L., \& Medin, D. L. (1985). The role of theories in conceptual coherence. Psychological Review, 92, 289-316.

Mussweiler, T. (2001). "Seek and ye shall find": Antecedents of assimilation and contrast in social comparison. European Journal of Social Psychology, 31, 499-509.

Mussweiler, T. (2003). Comparison processes in social judgment: Mechanisms and consequences. Psychological Review, 110, 472-489.

Nigro, G., \& Neisser, U. (1983). Point of view in personal memories. Cognitive Psychology, 15, 467-482.

Pillemer, D. B. (1998). Momentous events, vivid memories. Cambridge, MA: Harvard University Press.

Polivy, J., \& Herman, C. P. (2002). If at first you don't succeed: False hopes of self-change. American Psychologist, 57, 677-689.

Robinson, J. A., \& Swanson, K. L. (1993). Field and observer modes of remembering. Memory, 1, 169-184.

Ross, M. (1989). Relation of implicit theories to the construction of personal histories. Psychological Review, 96, 341-357.

Ross, M., \& Wilson, A. E. (2000). Constructing and appraising past selves. In D. L. Schacter \& E. Scarry (Eds.), Memory, brain, and belief (pp. 231-258). Cambridge, MA: Harvard University Press.

Ross, M., \& Wilson, A. E. (2002). It feels like yesterday: Self-esteem, valence of personal past experiences, and judgments of subjective distance. Journal of Personality and Social Psychology, 82, 792-803.

Rothman, A. J. (2000). Toward a theory-based analysis of behavioral maintenance. Health Psychology, 19, 64-69.

Sanitioso, R., Kunda, Z., \& Fong, G. T. (1990). Motivated recruitment of autobiographical memories. Journal of Personality and Social Psychology, 59, 229-241.

Schacter, D. L. (1996). Searching for memory: The brain, the mind, and the past. New York: Basic Books.

Schwarz, N., Bless, H., Strack, F., Klumpp, G., Rittenauer-Schatka, G., \& Simons, A. (1991). Ease of retrieval of information: Another look at the 
availability heuristic. Journal of Personality and Social Psychology, 61, 195-202.

Strack, F., Schwarz, N., \& Gschneidinger, E. (1985). Happiness and reminiscing: The role of time perspective, affect and mode of thinking. Journal of Personality and Social Psychology, 49, 1460-1469.

Trope, Y., \& Liberman, N. (2003). Temporal construal. Psychological Review, 110, 403-421.

Tversky, A. (1977). Features of similarity. Psychological Review, 84, 327-352.

Vallacher, R. R., \& Wegner, D. M. (1985). A theory of action identification. Hillsdale, NJ: Erlbaum.

Vinitzky-Seroussi, V. (1998). After pomp and circumstance: High school reunion as autobiographical occasion. Chicago: University of Chicago Press.
Wilson, A. E. (2000). How do people's perceptions of their former selves affect their current self-appraisals? Unpublished doctoral dissertation, University of Waterloo, Ontario, Canada.

Wilson, A. E., \& Ross, M. (2000). The frequency of temporal self and social comparisons in people's personal appraisals. Journal of Personality and Social Psychology, 78, 928-942.

Wilson, A. E., \& Ross, M. (2001). From chump to champ: People's appraisals of their earlier and current selves. Journal of Personality and Social Psychology, 80, 572-584.

Received September 24, 2003

Revision received August 4, 2004

Accepted August 10, 2004

\section{Wanted: Old APA Journals!}

APA is continuing its efforts to digitize older journal issues for the PsycARTICLES database. Thanks to many generous donors, we have made great strides, but we still need many issues, particularly those published in the 1950 s and earlier.

If you have a collection of older journals and are interested in making a donation, please e-mail journals@apa.org or visit http://www.apa.org/journals/donations.html for an up-to-date list of the issues we are seeking. 